\title{
Municipally sponsored human papillomavirus (HPV) vaccination of boys in Slovenia: the first 4 years
}

\author{
Majda Troha ${ }^{1 凶}$, Anja Šterbenc ${ }^{2}$, Martina Mlaker ${ }^{3}$, Mario Poljak $^{2}$
}

\begin{abstract}
Introduction: Human papillomavirus (HPV) vaccination was included in the national vaccination program in Slovenia in the $2009 / 2010$ school year. It is recommended for girls attending the sixth grade of primary school only and is fully state funded. Based on the initiative of school medicine specialists, Idrija and Cerkno were the first two municipalities to offer municipally sponsored HPV vaccination to boys in the 2014/2015 school year, showing promising results.

Methods: Our aim was to evaluate HPV vaccination coverage among boys attending the sixth grade who received the municipally sponsored HPV vaccine. Data were collected from corresponding physicians from different municipalities. Boys who received less than two doses of HPV vaccine or were HPV vaccinated against payment were excluded from this analysis.

Results: The number of municipalities that offer sponsored HPV vaccination of boys increased from two in $2014 / 2015$ to 10 in the $2017 / 2018$ school year. Although the proportion of vaccinated boys was initially relatively low, most municipalities attained at least $50 \%$ vaccination coverage rates, which is similar to the current HPV vaccination coverage of girls in Slovenia.

Conclusions: Our data show that the outstanding local initiative by several pediatricians and school medicine specialists can result in HPV vaccine coverage rates of boys that are comparable to or even higher than those in the national vaccination program for girls. Because acceptance of HPV vaccination among boys in Slovenia is adequate, we believe that the inclusion of boys in the national vaccination program, predicted to occur in the $2020 / 2021$ school year, will yield significant results.
\end{abstract}

Keywords: HPV, vaccination, boys, municipally sponsored vaccine, Slovenia

Received: 3 May 2019| Returned for modification: 19 May 2019| Accepted: 31 May 2019

\section{Introduction}

Infection with human papillomaviruses (HPV) is the most common sexually transmitted infection, affecting both men and women. Infection with high-risk HPV types (mainly HPV16 and HPV18) can lead to the development of various HPV-related precancerous and cancerous lesions, contributing to a considerable proportion of the global cancer burden among both sexes (1). Whereas cervical cancer is the second most common cancer to affect women aged 15 to 44 in the European Union, men are disproportionally affected by HPV-related oropharyngeal cancer $(1,2)$. In addition, anogenital warts and recurrent respiratory papillomatosis also affect both sexes. The burden of anogenital warts etiologically linked with low-risk HPV types (mainly HPV6 and HPV11) is staggering-approximately 680,344 to 844,391 new cases of anogenital warts could have been prevented per year in Europe only using the quadrivalent/nonavalent HPV vaccine (3).

Approximately half of countries worldwide, including all members of European Union, have implemented HPV vaccination into their national vaccination programs (4). In Slovenia, HPV vaccination was introduced into the national vaccination program in the 2009/2010 school year. It became the first non-mandatory statefunded vaccine in Slovenia, recommended for girls attending the sixth grade of primary school. Despite being fully state funded, the uptake of HPV vaccine among Slovenian girls remains around $50 \%$, with marked differences among different regions and even among different municipalities within the same region (5).

Although initially promoted as a vaccine against cervical cancer, it has become clear in recent years that the prevention potential of HPV vaccines far exceeds its original indications. However, similarly to Slovenia, the majority of national HPV vaccination programs in Europe provide free HPV vaccination to girls only $(3,4)$. Despite initiatives by pediatricians and school medicine specialists, and overwhelming data on the importance of genderneutral vaccination, especially if vaccination coverage of girls is below 50\% (6), boys are not yet included in the Slovenian national vaccination program. Moreover, due to the suboptimal HPV vaccination coverage of girls, it is highly unlikely that significant herd immunity has been established in the Slovenian population. Thus, following the previous success of municipally sponsored HPV vaccination for girls before the advent of the national HPV immunization program, some school medicine specialists decided to apply for municipal funds to cover the costs of vaccinating boys. Idrija and Cerkno were the first municipalities to offer sponsored HPV vaccination to boys in the 2014/2015 school year, showing promising results. Other municipalities soon followed. Hence, the aim of this study was to evaluate the acceptance and HPV vaccine coverage rates among boys that were offered the municipally sponsored HPV vaccine in Slovenia.

\section{Methods}

Only municipalities that provided free vaccination with at least two doses of quadrivalent (2014/2015 and 2015/2016 school years) or nonavalent (2016/2017 and 2017/2018 school years) HPV vaccine were included in the study. Similar to girls, boys were offered municipally funded HPV vaccination at the preventive care visit in the sixth grade after obtaining a parent's consent. In order to evaluate HPV vaccination coverage rates among boys attending the sixth grade, each of the corresponding pediatricians and/or 
school medicine specialists from all municipalities that provided municipally sponsored HPV vaccination were contacted. The medical records of all eligible boys attending the sixth grade were reviewed and data on the vaccination status were recorded. Boys who received fewer than two doses of HPV vaccine or were HPVvaccinated against payment were excluded from this analysis. All data were analyzed anonymously.

\section{Results}

The map of Slovenian municipalities that provide municipally funded HPV vaccination for boys is presented in Figure 1. The number of municipalities that offer sponsored HPV vaccination to boys increased from two in 2014/2015 to 10 in the 2017/2018 school year (Fig. 1). The greatest increase in the number of municipalities providing sponsored HPV vaccination for boys was seen in the 2016/2017 school year, when six municipalities decided on HPV vaccination. Table 1 presents the total number of eligible boys and the proportion of HPV-vaccinated boys in each municipality. Although the proportion of vaccinated boys was initially relatively low, ranging from $19 \%$ to $33 \%$, HPV vaccine coverage rates among boys increased during 2016/2017 and 2017/2018, with five out of eight municipalities reaching over half of eligible boys in 2016/2017, which is similar to the overall HPV vaccination coverage rates of girls attending the sixth grade and participating in the national vaccination program. In the following school year, HPV vaccination coverage rates remained relatively stable, with the most pronounced increase in HPV vaccination rate among boys from the Municipality of Ormož (from $27 \%$ to $69 \%$ ).

\section{Discussion}

In the 2006/2007 school year, shortly after first HPV vaccine became available, several school medicine specialists and pediatricians in Slovenia successfully applied for municipal funds to provide HPV vaccination for girls before HPV vaccination became part of the national vaccination program. When HPV vaccination was finally included in the national program in the 2009/2010 school year, all efforts focused on obtaining the highest possible vaccination coverage rates among girls attending the sixth grade. With mounting evidence regarding the burden of HPV-related disease and suboptimal vaccination coverage rates among girls in the national vaccination program, it has become clear that boys also need to be vaccinated against HPV. Based on the success of the initial efforts for girls, the same physicians again applied for municipal funds, this time to cover expenses for HPV vaccination of boys.

With this study we have shown that physicians, municipalities, and parents are inclined toward HPV vaccination of boys. Despite being available only since the 2014/2015 school year, municipally funded HPV vaccination for boys has achieved admirable results: the number of municipalities that offer sponsored HPV vaccine for boys increased from two to 10 in just 4 years (Fig. 1). Although sponsored HPV vaccination is usually more accessible in high-income countries and/or regions, we have shown that even small municipalities with a limited municipal budget can secure enough funds for HPV vaccination of boys. We are fully aware that this approach is far from ideal; it is not sustainable, and it creates substantial inequities based on where boys are attending prima-

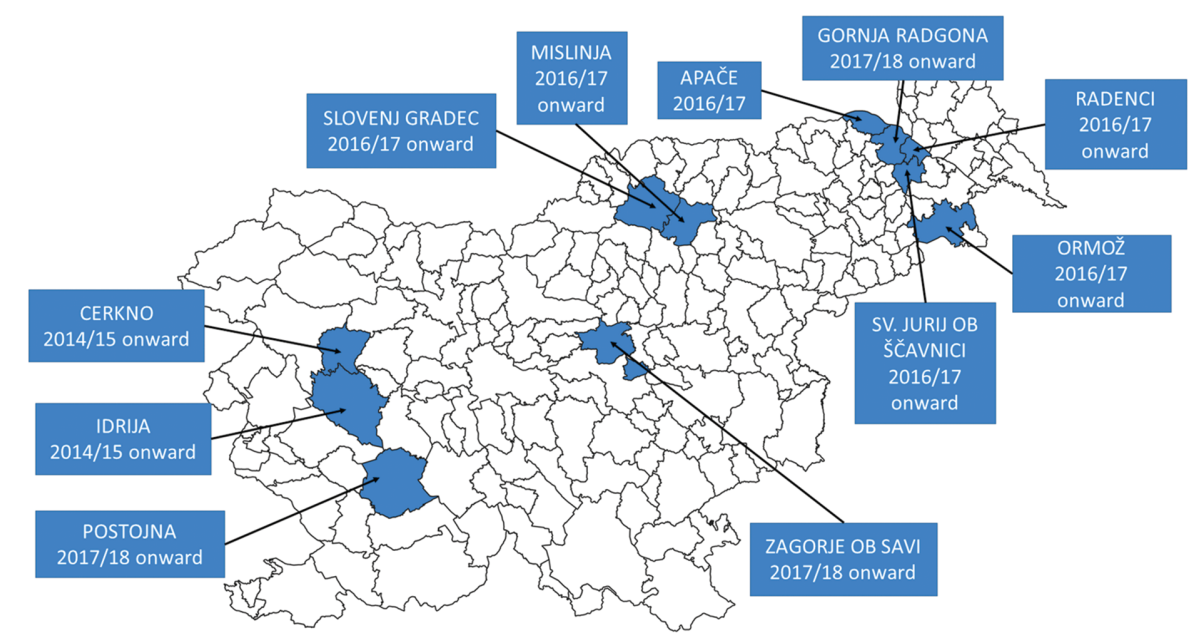

Figure 1 | Map of municipalities that provide funded HPV vaccination for boys and their years of participation.

Table 1 | Slovenian municipalities that provide free HPV vaccination for boys and corresponding HPV vaccine coverage rates.

\begin{tabular}{|c|c|c|c|c|c|c|c|c|}
\hline \multirow[b]{2}{*}{ Municipality } & \multicolumn{2}{|c|}{ 2014/15 school year } & \multicolumn{2}{|c|}{ 2015/16 school year } & \multicolumn{2}{|c|}{ 2016/17 school year } & \multicolumn{2}{|c|}{$2017 / 18$ school year } \\
\hline & $\begin{array}{c}\text { Total boys } \\
n\end{array}$ & $\begin{array}{c}\text { Vaccinated } \\
n(\%)\end{array}$ & $\begin{array}{c}\text { Total boys } \\
n\end{array}$ & $\begin{array}{c}\text { Vaccinated } \\
n(\%)\end{array}$ & $\begin{array}{c}\text { Total boys } \\
n\end{array}$ & $\begin{array}{c}\text { Vaccinated } \\
n(\%)\end{array}$ & $\begin{array}{c}\text { Total boys } \\
n\end{array}$ & $\begin{array}{c}\text { Vaccinated } \\
n(\%)\end{array}$ \\
\hline Idrija & 57 & $11(19)$ & 56 & $12(21)$ & 51 & $29(57)$ & 52 & $30(55)$ \\
\hline Cerkno & 19 & $4(21)$ & 18 & $6(33)$ & 22 & $8(40)$ & 21 & $7(37)$ \\
\hline Mislinja & - & - & - & - & 20 & $11(55)$ & 19 & $9(47)$ \\
\hline Slovenj Gradec & - & - & - & - & 87 & $52(60)$ & 88 & $50(57)$ \\
\hline Ormož & - & - & - & - & 71 & $19(27)$ & 71 & $49(69)$ \\
\hline Radenci & - & - & - & - & 19 & $13(68)$ & 25 & $10(40)$ \\
\hline Sv. Jurij ob Ščavnici & - & - & - & - & 16 & $12(75)$ & 13 & $6(46)$ \\
\hline Apače & - & - & - & - & 10 & $4(40)$ & - & - \\
\hline Gornja Radgona & - & - & - & - & - & - & 31 & $11(36)$ \\
\hline Zagorje ob Savi & - & - & - & - & - & - & 79 & $20(25)$ \\
\hline Postojna & - & - & - & - & - & - & 73 & $21(29)$ \\
\hline
\end{tabular}

- = no municipally sponsored HPV vaccination for boys. 
ry school. Although inclusion of boys in the Slovenian national HPV vaccination program is the most optimal strategic approach because it eliminates social and gender inequities, municipally sponsored HPV vaccination of boys may, in the meantime, serve as a bridge to gender-neutral vaccination.

Almost all municipalities reached at least 50\% vaccination coverage rates (Table 1). The substantial increase in HPV vaccination coverage from $27 \%$ to $69 \%$ in the Municipality of Ormož clearly shows that HPV vaccination rates are largely influenced by the knowledge of and attitude toward HPV vaccination of the school medicine specialist or pediatrician that provides the immunization program in a particular school. Moreover, data from this study clearly disprove one of the main concerns raised by some skeptics: that if boys were also included in the national HPV vaccination program, the coverage rates would be even lower than the already relatively low coverage rate of girls, claiming inclusion of boys in the national HPV vaccination program would yield no additional benefits. However, we have shown that the acceptance of municipally sponsored HPV vaccination of boys is comparable to or even higher than the national coverage in girls. Furthermore, some physicians who vaccinated these boys indeed also started to notice a trend toward higher HPV vaccine acceptance among girls following implementation of gender-neutral vaccination (data not shown). This is in line with previous reports suggesting that the acceptance of HPV vaccine might increase if the vaccine is offered to both sexes (7). Moreover, a recent Swedish study (8) showed that boys are generally in favor of free HPV vaccination within the national vaccination program. The reasons for vaccine acceptance were mainly altruistic; that is, promotion of public health, prevention of HPV-related neoplasms, and protection of their sexual partners. Notably, boys also perceived genderneutral HPV vaccination as a matter of equal rights, particularly because HPV-related diseases affect both sexes (8). In addition, a pan-European cross-sectional survey on parental attitudes toward male HPV vaccination has shown that, following brief information about HPV-related disease in both sexes, the majority of parents are in favor of HPV vaccination of their sons with acceptance rates that were similar to those in girls (9). Our results are in line with these observations, showing a positive attitude of parents toward gender-neutral HPV vaccination.

Unfortunately, HPV vaccination coverage of girls remains low to moderate in most countries with a nationally implemented HPV vaccination program, with only $1.4 \%$ of all eligible females worldwide having received a full course of HPV vaccination $(10,11)$. It has previously been shown that girls-only HPV vaccination programs have the potential to induce herd effects if the coverage is high, also extending the protection to unvaccinated females and/ or males (12). Interestingly, reductions in the incidence of anogenital warts were noted even in countries where only approximately $30 \%$ of eligible girls were vaccinated against HPV, although these reductions were significantly less evident than in countries with high overall coverage, such as Australia or Scotland $(13,14)$, with no indication of cross-protection or herd effects $(15,16)$. Thus, gender-neutral vaccination of early adolescents has the potential to maximize herd effects against vaccine HPV types in countries with low to moderate vaccination coverage. Moreover, high coverage in men appears to be crucial for also providing a substantial public health benefit to unvaccinated women $(15,16)$.

Since the approval of the first HPV vaccine in 2006, there has been an increasing body of evidence regarding the burden of HPVrelated cancers in men (18). In 2009, the Food and Drug Admin- istration (FDA) extended the approval of the quadrivalent HPV vaccine to also include boys and men. The indications of the nonavalent HPV vaccine, first approved in 2014, were extended by including boys and men in 2015. Gender-neutral vaccination is an invaluable method for preventing HPV-related disease and is currently carried out in more than 20 countries, including Australia, Austria, Bermuda, Brazil, Canada, Croatia, the Czech Republic, Germany, Israel, Italy, Liechtenstein, New Zealand, Norway, Switzerland, the United Kingdom, and the United States $(18,19)$. Australia has been a pioneer with respect to implementing HPV vaccination-it was one of the first countries to introduce a national HPV vaccination program for girls and young women, and one of the most successful ones in sustaining high vaccination coverage rates among the target population. Despite achieving high vaccine uptake among girls, Australia was the first country to expand eligibility for government-funded universal vaccination to boys in 2013. This decision was considered crucial for reasons of equity, especially because of the substantial HPV-related disease burden in males and due to the fact that indirect benefits of herd protection among men who have sex with men (MSM) are limited in female-only HPV vaccination programs. Moreover, an additional reduction in the prevalence of HPV infections and incidence of HPV-related disease (e.g., the incidence of anogenital warts) in women was expected with the advent of gender-neutral vaccination. Moreover, if the vaccination coverage reaches $80 \%$ in both sexes, HPV vaccine types could be eliminated if the vaccines confer long-lasting protection (19). One of the most recent countries to announce the extension of HPV vaccination program to teenage boys is Northern Ireland, which will offer the HPV vaccine to all boys in year 9 at school from the 2019/2020 school year onward (20). HPV vaccination of males is of utmost importance because cases of oral cancer are skyrocketing, especially among males. In the US and Wales, the incidence of oropharyngeal cancers in males has already surpassed the incidence of cervical cancer $(21,22)$. Alarmingly, oral cancer now claims even more lives than car accidents in Northern Ireland (20). Whereas in women naturally induced anti-HPV antibodies confer some level of protection against subsequent HPV acquisition and progression to precancerous and cancerous lesions, the protection in men is less pronounced because only a minority of infected men develop anti-HPV antibodies, leaving them largely unprotected against subsequent infection and consequent HPV-related diseases $(15,23)$.

Thus, gender-neutral HPV vaccination ensures greater gender equity in the prevention of HPV-related disease. Boys and men should also be able to reduce their personal risk of HPV disease through vaccination, especially in high-risk groups such as MSM. Although women have traditionally been responsible for reproductive health, it is unfair for women to assume all the responsibility for preventing HPV-related diseases and other sexually transmitted infections (24). However, one major argument against implementing gender-neutral HPV vaccination has been the cost of sustaining such programs. Although initial studies did not identify gender-neutral HPV vaccination as cost-effective, numerous recent studies have refuted previous observations, proving that such an approach is indeed cost-effective, especially if the costs of treatment of oropharyngeal cancer and anogenital warts and the reduced number of doses of the vaccine needed are included in the mathematical models (25). Thus, in April 2019, the European Centre for Disease Prevention and Control (ECDC) launched a public consultation on the draft guidance for introducing HPV vaccines in EU countries with a focus on the nonava- 
lent HPV vaccine and vaccination of boys and people living with HIV. The draft conclusions state that the addition of males to current national female-only HPV vaccination programs becomes increasingly more cost-effective with persistently lower vaccination coverage among females and lower HPV vaccine cost. Moreover, it has become clear that, if the objective of the HPV vaccination program is to prevent all HPV-associated disease, gender-neutral HPV vaccination seems to be the most cost-effective strategy (26). Hence, we believe that gender-neutral HPV vaccination should be promptly implemented in the Slovenian national program vaccination program.

\section{Conclusions}

The exclusion of preadolescent boys from national HPV immunization programs has raised equity concerns: HPV vaccines have the ability to prevent HPV-related diseases in both sexes, especially in countries with girls-only programs where the HPV vaccine uptake has been too low to establish full indirect herd protection of men. The proportion of boys receiving municipally sponsored HPV vaccination in Slovenia during the last few years has ranged from $25 \%$ to $69 \%$, suggesting that a significant proportion of boys can be reached using this approach. Our data thus reaffirm the fact that implementation of gender-neutral HPV vaccination in Slovenia will provide important additional protection against HPV-related disease in vaccine-eligible cohorts. In May 2019, the implementation process of gender-neutral HPV vaccination finally started in Slovenia. It is predicted that boys could be included in the national vaccination scheme from 2020/21 onward. Although municipally sponsored HPV vaccination of boys is not an optimal solution, it may serve as a bridge to gender-neutral vaccination.

\section{Acknowledgments}

We would like to thank all school medicine specialists and pediatricians who provided their data on HPV coverage rates among boys; namely, Majda Troha (Idrija and Cerkno), Martina Mlaker (Radenci), Mateja Bec (Zagorje ob Savi), Orhideja Dimc (Postojna), Vladana Đurić Kosič (Gornja Radgona), Miroslava Cajnkar Kac (Slovenj Gradec and Mislinja), Zlata Polak Vičar (Ormož), and Maja Klemenčič (Apače and Sv. Jurij ob Ščavnici). Their outstanding enthusiasm, promotion of gender-neutral HPV vaccination, and continuous efforts toward securing municipal funds for HPV vaccination of boys is greatly appreciated. In addition, we would like to thank Tomaž Mark Zorec for his help with designing the map of municipalities that provide free HPV vaccination for boys.

\section{References}

1. de Martel C, Plummer M, Vignat J, Franceschi S. Worldwide burden of cancer attributable to HPV by site, country and HPV type. Int I Cancer. 2017;141:664-70.

2. Bruni L, Albero G, Serrano B, Mena M, Gómez D, Muñoz J, et al. ICO/IARC Information Centre on HPV and Cancer (HPV Information Centre). Human Papillomavirus and Related Diseases in Europe. Summary Report 17 June 2019.

3. Hartwig S, St Guily JL, Dominiak-Felden G, Alemany L, de Sanjosé S. Estimation of the overall burden of cancers, precancerous lesions, and genital warts attributable to 9-valent HPV vaccine types in women and men in Europe. Infect Agent Cancer. 2017;12:19.

4. Oberlin AM, Rahangdale L, Chinula L, Fuseini NM, Chibwesha CJ. Making HPV vaccination available to girls everywhere. Int J Gynaecol Obstet. 2018;143:267-76.

5. Nacionalni inštitut za javno zdravje. Precepljenost deklic 6. Razredov osnovne šole, Slovenija, šolska leta 2013/14 - 2017/18 [Internet]. Ljubljana, Slovenia. [cited 2019 May 1]. Available from: https://www.nijz.si/sites/www.nijz.si/files/ uploaded/hpv_precepljenost_2013_2018.pdf.

6. Lehtinen M, Söderlund-Strand A, Vänskä S, Luostarinen T, Eriksson T, Natunen $\mathrm{K}$, et al. Impact of gender-neutral or girls-only vaccination against human papillomavirus-results of a community-randomized clinical trial (I). Int I Cancer. 2018;142:949-58.

7. Oteng B, Marra F, Lynd LD, Ogilvie G, Patrick D, Marra CA. Evaluating societal preferences for human papillomavirus vaccine and cervical smear test screening programme. Sex Transm Infect. 2011;87:52-7.

8. Grandahl M, Nevéus T, Dalianis T, Larsson M, Tydén T, Stenhammar C. "I also want to be vaccinated!"-adolescent boys' awareness and thoughts, perceived benefits, information sources, and intention to be vaccinated against human papillomavirus (HPV). Hum Vaccin Immunother. 2018; [Epub ahead of print].

9. Lee Mortensen G, Adam M, Idtaleb L. Parental attitudes towards male human papillomavirus vaccination: a pan-European cross-sectional survey. BMC Public Health. 2015;15:624.

10. Elfström KM, Dillner J, Arnheim-Dahlström L. Organization and quality of HPV vaccination programs in Europe. Vaccine. 2015;33:1673-81.

11. Bruni L, Diaz M, Barrionuevo-Rosas L, Herrero R, Bray F, Bosch FX, et al. Global estimates of human papillomavirus vaccination coverage by region and income level: a pooled analysis. Lancet Glob Health. 2016;4:e453-63.

12. Machalek DA, Chow EP, Garland SM, Wigan R, Cornall AM, Fairley CK, et al. Human papillomavirus prevalence in unvaccinated heterosexual men after a national female vaccination program. J Infect Dis. 2017;215:202-8.

13. Herweijer E, Ploner A, Sparén P. Substantially reduced incidence of genital warts in women and men six years after HPV vaccine availability in Sweden. Vaccine. 2018;36:1917-20.

14. Kavanagh K, Pollock KG, Cuschieri K, Palmer T, Cameron RL, Watt C, et al. Changes in the prevalence of human papillomavirus following a national bivalent human papillomavirus vaccination programme in Scotland: a 7-year cross-sectional study. Lancet Infect Dis. 2017;17:1293-302.
15. Lehtinen M, Luostarinen T, Vänskä S, Söderlund-Strand A, Eriksson T, Natunen $\mathrm{K}$, et al. Gender-neutral vaccination provides improved control of human papillomavirus types $18 / 31 / 33 / 35$ through herd immunity: results of a community randomized trial (III). Int J Cancer. 2018;143:2299-310.

16. Brisson M, Bénard É, Drolet M, Bogaards JA, Baussano I, Vänskä S, et al. Population-level impact, herd immunity, and elimination after human papillomavirus vaccination: a systematic review and meta-analysis of predictions from transmission-dynamic models. Lancet Public Health. 2016;1:8-17.

17. Powell N, Hibbitts S, Evans M. Gender neutral vaccination against HPV. BMJ. 2018;362:k3837.

18. Prue G, Baker P, Graham D, Nutting C, Greenhouse P, Lawler M. It is time for universal HPV vaccination. Lancet. 2018;392:913-4.

19. Patel C, Brotherton JM, Pillsbury A, Jayasinghe S, Donovan B, Macartney K, et al. The impact of 10 years of human papillomavirus (HPV) vaccination in Australia: what additional disease burden will a nonavalent vaccine prevent? Euro Surveill. 2018;23.

20. O’Dowd A. HPV vaccination for boys will happen in Northern Ireland. Br Dent J. 2019;226:554.

21. White C. Aggregated six head and neck cancer subsites: base of tongue (C01), oropharynx (C10), lingual tonsil (C02.1), soft palate (C05.1), uvula (C05.2), tonsil (Cog) for males, females, and persons in Wales, 2001-2015: numbers of cases and European age standardised rates per 100000 population. Welsh Cancer Intelligence and Surveillance Unit, Health Intelligence Division, Public Health Wales: Statistical Report, 2017;2644b.

22. Van Dyne EA, Henley SJ, Saraiya M, Thomas CC, Markowitz LE, Benard VB. Trends in human papillomavirus-associated cancers-United States, 1999-2015. MMWR Morb Mortal Wkly Rep. 2018;67:918-24.

23. Drolet M, Bénard É, Boily MC, Ali H, Baandrup L, Bauer H, et al. Populationlevel impact and herd effects following human papillomavirus vaccination programmes: a systematic review and meta-analysis. Lancet Infect Dis. 2015;15: $565-80$.

24. Giuliano AR, Lazcano-Ponce E, Villa LL, Flores R, Salmeron J, Lee JH, et al. The human papillomavirus infection in men study: human papillomavirus prevalence and type distribution among men residing in Brazil, Mexico, and the United States. Cancer Epidemiol Biomarkers Prev. 2008;17:2036-43.

25. Favato G, Easton T, Vecchiato R, Noikokyris E. Ecological validity of cost-effectiveness models of universal HPV vaccination: a systematic literature review. Vaccine. 2017;35:2622-32.

26. European Centre for Disease Prevention and Control. Public consultation on draft guidance for introduction of HPV vaccines in EU countries: focus on 9-valent HPV vaccine and vaccination of boys and people living with HIV [Internet]. Stockholm; 2019. [cited 2019 May 2]. Available from: https://ecdc.europa.eu/ sites/portal/files/documents/hpv-public-consultation-3-April.pdf. 